\title{
Strategies for G-protein coupled receptor deorphanization
}

Sorin Tunaru ${ }^{1 \star}$

${ }^{1}$ Institute for Heart and Lung Research, Department of Pharmacology, Ludwigstr. 43, 61231 Bad Nauheim, Germany

(Received 1 March, 2017; accepted 3 May, 2017)

\begin{abstract}
G-protein coupled receptors (GPCRs) form the largest group of transmembrane proteins in mammals, and they are major regulators of multiple cellular processes. Intense research performed in the last decades revealed their implication in pathophysiology and included many of their members as important drug targets. With the advent of genomics a large number of new GPCR genes have been discovered, however many of them still encode receptors for which no ligands and biological roles have yet been discovered. They are termed orphan GPCRs (oGPCRs) and are under intense scientific investigations by the pharma industry and academia to discover ligands and thus to determine their contribution to pathophysiology. Two strategies have been used to identify ligands of GPCRs, known as the reverse and forward pharmacology. Both of them are presented and discussed in this review.
\end{abstract}

Keywords: GPCR, deorphanization, reverse pharmacology, forward pharmacology, drug discovery

\section{INTRODUCTION}

G-protein coupled receptors are the largest superfamily of transmembrane receptors in eukaryotes. Their key structural signature is the presence of a seven transmembrane (7TM) domain which separates the extracellularly located $\mathrm{N}$-terminus from the intracellular C-terminus. Another property of GPCRs is that they mediate cellular effects of a cognate ligand by coupling to intracellular heterotrimeric guanine nucleotide binding proteins, or G-proteins, composed of $\alpha \beta \gamma$ subunits. Functionally, G-proteins can be grouped into four subtypes based on the structural and functional similarities of their $\alpha$-subunit: $\mathrm{Gq} / 11$, mediating intracellular calcium increase; Gs, activating adenylyl-cyclases (ACs) and increasing cytosolic cyclic adenosine monophosphate (cAMP) in cells; Gi, negative regulators of ACs, thus reducing intracellular cAMP concentration and G12/13, mediating cytoskeletal remodeling cellular motility $(1,2)$.

GPCRs are key mediators in the regulation of a variety of physiological processes and also participate in a multitude of diseases. They are required for the function of complex senses such as olfaction, taste, or visual perception. Moreover, their role in the regulation of blood pressure, kidney function, cancer progression and allergic reactions has been well documented (3). As a consequence of their biological importance, more than $40 \%$ of the world-wide approved drugs target GPCRs either as agonists or antagonists. Several examples of commercially approved drugs targeting GPCRs and their therapeutic effects can be found in the Table 1. Although GPCRs are the most prominent drug target, with a market value of over 65 billion dollars in annual sales (4), almost 140 genes in human genome still encode receptors for which neither biological roles nor endogenous ligands have been identified, termed orphan GPCRs (oGPCRs) $(5,6)$.

GPCR deorphanization started in 1986, when the primary structure of the $\beta$-adrenergic receptor ( $\beta$-AR) was characterized. Surprisingly, its amino-acid sequence not only shared high homology with the sequence of visual rhodopsin but also shared a common secondary structure, the 7TM domain (7). This seminal finding led to the concept that all plasma membrane 7TM proteins which are able to interact with G-proteins, belong to a superfamily of receptors. At that time it was already thought that a number of biologically active metabolites, such as acetylcholine, eicosanoids (especially prostaglandins), biogenic amines and hormones were inducing effects by acting as ligands of GPCRs. Newly developed molecular biology techniques, such as degenerated PCR and low-stringency hybridization, were successfully used to

${ }^{*}$ Corresponding author ( Sorin Tunaru, Department of Pharmacology, Max-Planck-Institute for Heart and Lung Research, Ludwigstr. 43 , 61231 Bad Nauheim, Germany; Phone: +49-(0)6032-705-1210, Fax: +49-(0)6032-705-1204, E-mail: sorin.tunaru@mpi-bn.mpg.de) 
identify new receptors, with different homologies to $\beta$-AR (8). Moreover, with the expansion of genomics at the turn of the century, a large number of potential GPCR genes were identified, reaching almost 900 in human and over 1000 in mouse, including olfactory receptors (9-11). Due to the large number of GPCR genes discovered, some of them were abbreviated as "GPR" followed by a number, as in the case of GPR81 or GPR37 and so on. However, this terminology does not necessarily reflect any degree of relatedness among them.

In the last decades, huge efforts by the academia and pharma industry have been made to identify endogenous ligands and agonists of oGPCRs and by this to reveal their role in pathophysiology and to possibly include them in the druggable targets portfolio. The identification of modulators of oGPCRs can be a tedious and risky process and can reach tremendous costs at the risk of obtaining modest results, if any at all. Therapeutically, although the endogenous ligand of a potentially important oGPCR may remain unknown, the identification of a compound with agonistic properties can be considered a major success because it allows to directly testing its potential beneficial role.

Two main pharmacological strategies have been used in the last years for deorphanization, known as the reverse and the forward pharmacology. Both strategies will be presented in this article discussing their applicability in the orphan receptor research field.

\section{REVERSE PHARMACOLOGY}

The concept of reverse pharmacology, also known as target-based drug discovery, relies on the hypothesis that the modulatory effect of a protein (i.e., receptor, ion channel, enzyme and so on) will have important biological consequences which can be of therapeutic importance, thus becoming a pharmacological target (12). In other words, reverse pharmacology aims to identify compounds which can alter a chosen target's activity. In the case of GPCRs, the identification of the endogenous ligand and/or modulatory compounds, as its primary goal, serves two convergent objectives: firstly, the understanding of the cellular pathway the receptor is integrated into and its role in the regulation of a particular physiological process and secondly, it gives information on its possible therapeutic value. The most straightforward way to identify ligands at oGPCRs is to ectopically express them in a cellular system and to measure dependency of ligand-induced modulation of a signaling pathway on the presence of the receptor in quest (Fig. 1). In this strategy, the selected receptor is used as bait to identify ligands. Prior to ligand screening, several preliminary studies are usually performed or taken into account: 1) receptor lossof-function phenotyping, 2) receptor bioinformatics and 3) tissue expression analyses.
1) Loss-of-function studies by genetic deletion or mutational analysis can indicate whether an oGPCR plays an important role in the regulation of a physiological process. Several examples support the idea of genetic studies as valuable preliminary steps in the identification of potentially relevant oGPCRs: for example, mutations in the GPR101 gene, which is strongly expressed in the hypothalamus (13), have been associated with gigantism and acromegaly (14). In the case of GPR149, which shows expression in granulosa cells and oocytes, the gene-deficient mice showed increased fertility and enhanced ovulation (15). Disruption of another orphan receptor, GPR45, caused hypothalamic proopiomelanocortin (POMC) expression and obesity in mice (16) whereas mice lacking GPR21 receptor, which shows expression in the adipose tissue and liver, were resistant to diet-induced obesity and had increased glucose tolerance and insulin sensitivity (17). A compelling database of GPCR genes and known associated phenotypes can be found at IUPHAR database: http://www.guidetopharmacology.org.

2) Bioinformatics analysis can be used to compare sequences of oGPCRs with those of the liganded receptors to predict cognate ligands based on sequence homology. For example, the orphan receptor GPR105 (known as P2Y14) which showed significant homology with other nucleotide-liganded purinergic receptors was screened against a library containing nucleotide di- and triphosphate conjugates to identify UDP-glucose as ligand (18). Another example was the identification of sphingosine-1-phospahte (S1P) as a potent ligand of EDG-1 (S1P1) receptor (15) a finding which led to the subsequent discovery of multiple receptors (S1P1 to S1P5) receptors for S1P, based on sequence homology analyses (19-21). Furthermore, due to the success of resolving the $\beta 1$ - and $\beta 2-A R$ receptors crystal structures (22), followed by the X-ray structures of 20 receptors in the following years, structure-based drug design (SBDD) can be an effective tool to design potential agonists or antagonists $(23,24)$. Several examples where SBDD in conjuction with computer modelling has been successfully employed to find new ligands at known or orphan GPCRs are the identification of alloseric modulators and agonists of the proton receptors GPR68 and GPR65 (25). Another remarkable example with potential clinical relevance is the discovery through SBDD of a novel $\mu$-opioid receptor agonist which selectively drives Gi/o-mediated signaling while minimizing $\beta$-arrestin-dependent signaling pathways (26). Furthermore, 3D homology modelling of GPCRs using as templates crystal structure of numerous GPCRs represents an important tool for ligand prediction and identification and it has been already succesfully used in the past, for example, in the identification of a selective agonist of M1 acetylcholine receptor (27).

3) Tissue expression analysis of an oGPCR can provide valuable information about its potential biological role. 
Reverse Pharmacology

receptor selection
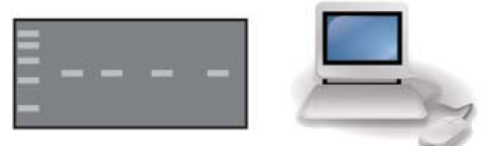

expression pattern bioinformatics
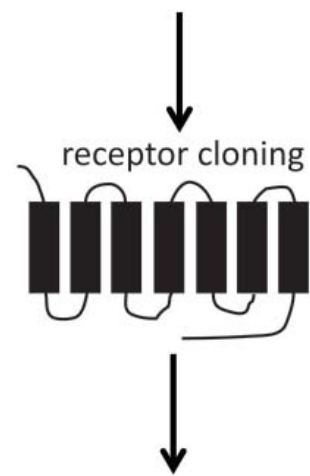

heterologous expreesion

functional screening

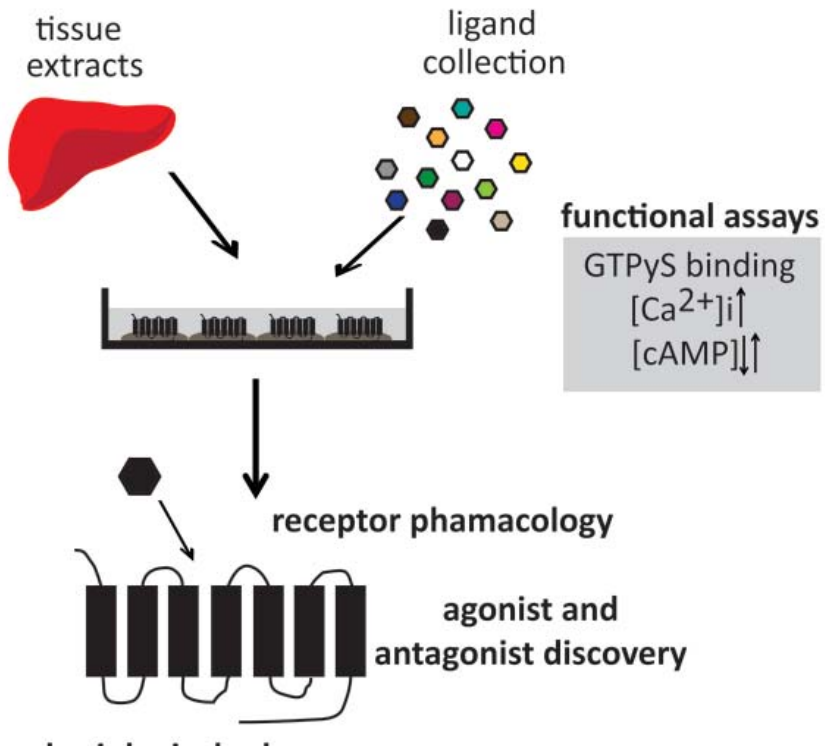

physiological relevance

\section{Forward Pharmacology}

ligand selection

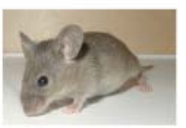

genetics

databases search published reports

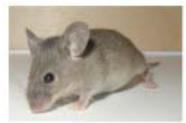

biological activity

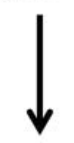

in vitro functional assays and ligand validation
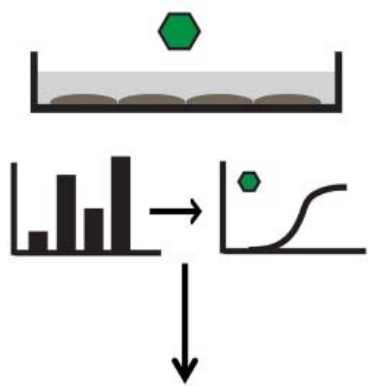

generation and screening receptor library

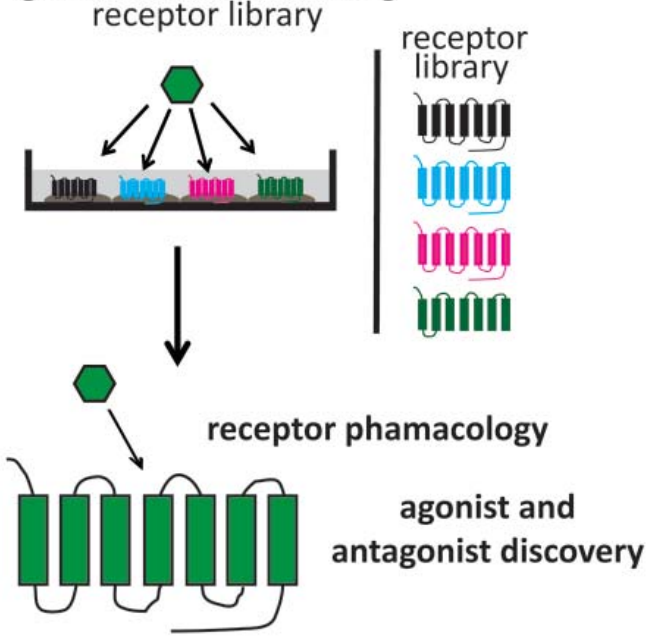

physiological relevance

Fig. 1. - Flow charts of the reverse and forward pharmacology strategies to identify novel receptor-ligand pairs. Reverse pharmacology is used to identify ligands of selected receptors whereas the forward pharmacology focuses on the identification of receptors for selected ligands.

The expression data are usually combined with genetic studies to acquire more information of the receptor's biological importance. Compelling expression studies of GPCRs in mouse (including oGPCRs) have been made $(28,29)$. Other resources exist, such as the Allen Brain Atlas (http://www.brain-map.org/).

Once the receptor is chosen based on its potential biological relevance, deorphanization process requires the application of two technologies: a) generation of a suitable compound/metabolite library to be screened and b) measuring receptor activation following ligands stimulation.

a) Generation of a suitable and complex ligand library can sometimes be challenging due to the limited availability and high costs of some compounds of interest. However, in the last years a number of companies provide ready-to-use or even custom-designed libraries. If the library is to be custom-designed, the selection criteria of the substances and/or metabolites are usually based on public information on described effects of metabolites 
Table 1. Example of approved drugs targeting GPCRs and their therapeutic applications.

\begin{tabular}{|l|l|l|l|}
\hline Trade Name & GPCR Target & agonist & asthma \\
\hline Albuterol & adrenergic- $\beta_{2}$ & antagonist & angina pectoris \\
\hline Alprenolol & adrenergic- $\beta_{1-3} / 5-\mathrm{HT}_{1 \mathrm{~A}}$ & agonist & gastric dysfunctions \\
\hline Amthamine & histamine- $\mathrm{H}_{2}$ & agonist & high blood pressure; anxiety, migraine \\
\hline Baclofen (Lioresal) & gamma-aminobutyric-GABAB & agonist & skeletal muscle relaxant \\
\hline Clonidine & adrenergic- $\alpha_{2}$ & antagonist & allergy \\
\hline Cetirizine & histamine- $\mathrm{H}_{1}$ & antagonist & peptic ulcer disease \\
\hline Famotidine & histamine- $\mathrm{H}_{2}$ & antagonist & acute asthma \\
\hline Ipratropium (Atrovent) & muscarinic- $\mathrm{H}_{3}$ & antagonist & hypertension \\
\hline Irbesartan & angiotensin- $\mathrm{AT}_{2}$ & antagonist & allergic conjunctivitis \\
\hline Ketotifen & histamine- $\mathrm{H}_{1}$ & antagonist & hypertension \\
\hline Losartan & angiotensin- $-\mathrm{AT}_{2}$ & agonist & pain \\
\hline Morphine & $\mu$-opioid & agonist & antiatherogenic \\
\hline Niaspan & HCAR & agonist & asthma \\
\hline Procaterol & adrenergic- $\beta_{2}$ & antagonist & peptic ulcer \\
\hline Ranitidine (Zantac) & histamine- $\mathrm{H}_{2}$ & antagonist & schizophrenia; bipolar \\
\hline Risperidone & dopamine- $\mathrm{D}_{2} /$ serotonine-5HT & agonist & laxation; labour \\
\hline Ricinoleic acid & prostaglandin $\mathrm{E}_{2}$-EP & & \\
\hline
\end{tabular}

at tissue or cellular level. One advantage of the library-based approach is that the purified compounds can be tested at relatively high concentrations. By screening ligand libraries, a large number of receptors were deorphanized such as receptors for short-chain fatty acids (30) or the receptor for polyunsaturated fatty acids (PUFAs) expressed in the pancreatic islets, known as FFAR1 (GPR40), which enhances glucose-induced insulin secretion after PUFAs stimulation $(31,32)$. A complementary approach to library-based strategy is to test fractions from extracts of tissues/organs where the receptor is highly expressed followed by the isolation and purification of the endogenous ligand(s). Examples are the identification of novel neuropeptides from tissue fractions and their receptors, especially those involved in the regulation of food intake and behavior such as orexin and orexin receptors (33) and the melanin-concentrating hormone $(\mathrm{MCH})$ and its receptor, $\mathrm{MCH} 1(34,35)$. Orexin and $\mathrm{MCH}$ systems are also orexigenic, as genetic inactivation of one of the receptors or peptide ligands led to lean phenotypes in mouse. However, the use of tissue/organ extract as a source of endogenous ligands can be complicated by the fact that some ligands act in paracrine manner, being synthesized in a different organ than their site of action. An example is the anorexigenic peptide ghrelin which is produced in the stomach and functions as an endogenous ligand of the growth hormone secretagogue (GHS) receptor expressed primarily in the pituitary gland and the hypothalamus $(36,37)$.

(b) Determination of receptor activation after stimulation with ligands or tissue fractions relies on canonical intracellular signaling pathways modulated by heterologously expressed GPCR and G-proteins (31). However, one of the first challenges the investigator has to face is to ensure that the overexpressed receptor to be studied traffics to the plasma membrane. It is well known that some GPCRs, when ectopically expressed in one of the standard reporter cell lines such as COS-1, HEK293 or $\mathrm{CHO}$ fail to reach plasma membrane because of a lack of an interaction partner such as receptor activity-modifying proteins (RAMPs) $(39,40)$.

Methods to determine the activity of a GPCR rely on the G-protein-promoted activation of different intracellular signaling cascades after receptor activation and typically include: (i) GTP $\gamma$ S binding assay on membranes of cells expressing an oGPCR; (ii) determination of intracellular calcium transients as a result of receptor activation; and (iii) modulation of intracellular cAMP levels after activation of Gs- and Gi-coupled receptors.

(i) GTP $\gamma \mathrm{S}$ binding assay measures the guanine nucleotide exchange of $\mathrm{G} \gamma$ subunit (GDP to GTP exchange) as it is the earliest event of the activated receptor. Thus, it is not subject to amplification by other cellular processes providing "true" determinations of the efficacies and potencies of a ligand. GTP $\gamma S$ binding measures the accumulation of a non-hydrolysable analog of GTP, $\left[{ }^{35} \mathrm{~S}\right]-\mathrm{GTP} \gamma \mathrm{S}$ on the membrane of cells expressing a receptor. The main advantage of this assay is that it allows discriminating between agonists, antagonists and inverse agonists (an agonist which decreases the basal activity of a constitutively active receptor). GTP $\gamma S$ binding assay depends also on the relative abundance 
of endogenously expressed G-proteins. As a results, it is more suitable for studying $\mathrm{Gi} / \mathrm{o}$-coupled receptors due to the higher cellular levels of Gi/o proteins (41). Beside the need of a radioactive tracer, a disadvantage of this method is the use of a final filtration step to separate bound from free $\left[{ }^{35} \mathrm{~S}\right]-\mathrm{GTP} \gamma \mathrm{S}$, thus limiting its high-throughput capabilities. However, this assay has been successfully used to identify ligands at oGPCRs (42). To address some of these issues, Perkin Elmer has released a non-radioactive time-resolved fluorescence (TRF) GTP-binding assay using europium-labeled GTP (DELFIA ${ }^{\mathrm{TM}}$ ). The fluorescence recorded is directly proportional with the amount of Eu-GTP accumulated in membranes from cells expressing a receptor and thus reflects receptor activation. Although it still requires the washing step, it has been successfully validated on a number of receptor targets such as serotonin 5-HT5a, $\alpha 2$-adrenergic, dopamine and muscarinic receptors (43).

(ii) Intracellular calcium assay is one of the most versatile and cost-efficient screening methods used in reverse pharmacology for receptor deorphanization and characterization. It relies on the property of Gq-coupled receptors to activate an intracellular signaling pathway which includes activation of phospholipase C, isoform $\beta\left(\mathrm{PLC}_{\beta}\right)$ with generation of diacylglycerol (DAG) and inositol triphosphate $\left(\mathrm{IP}_{3}\right)$ which in turn triggers the release of endoplasmic-reticulum (ER)-stored calcium by binding to IP3 receptors. The basis of this assay is the heterologous expression of a target receptor in a cell line and determination of $\left[\mathrm{Ca}^{2+}\right] \mathrm{i}$ by specific probes which can be chemical (fluorescent) or genetic. Chemical fluorescent calcium indicators have been used for decades to measure free intracellular $\mathrm{Ca}^{2+}$ concentrations in cells. They are cell permeant acetoxymethyl (AM) esters such as Fura-2/AM, Fluo-4/AM to Fluo-8/AM generation of indicators (44). Their main advantage is that they do not require being transfected. It is the method of choice for fluorometric imaging plate readers (FLIPR)-based assays used in the pharma industry where large compound libraries are screened. The main disadvantage of the fluorescent calcium indicators is the lower signal-to-noise ratio and their tendency to mislocalize to subcellular compartments. In contrast to chemical probes, calcium-sensitive genetic probes offer several advantages over fluorescent probes. They are based on the calcium sensitive photoprotein, aequorin, which is expressed in the jellyfish Aequorea victoria. One of the best probes consists of a fusion protein between aequorin and the green fluorescent protein (GFP) separated by a short linker (45). The main advantage over chemical fluorescent probes is the absence of a significant background and the very high signal-to-noise ratio. In this assay, a receptor of interest is transfected together with the genetic probe and $48 \mathrm{~h}$ later the functional aequorin is reconstituted by the addition of a cofactor, coelenterazine $h$. The functional assay is usually performed in a luminometer equipped with ligand dispensing capabilities in a 96, 384 or 1536 well format. This type of assay has been successfully used to find a large number of ligands and agonists of orphan and known GPCRs (46).

(iii) cAMP assay is suitable for measuring activated Gs- and Gi-coupled receptors which are known to either increase (Gs) or decrease (Gi/o) intracellular cAMP concentration after activation by a ligand. To determine the activation of Gs-coupled receptors, cells overexpressing a receptor are stimulated with the candidate compound and the intracellular accumulation of cAMP is determined 15 minutes later. To determine the activation of Gi-coupled receptors, cells need to be pre-stimulated with the ligand of interest for 5 minutes followed by stimulation with a Gs-independent activator of AC, forskolin and determination of cAMP levels 15 minutes later. Although forskolin works well in most of the cases, a more physiological approach would be to use a GPCR-mediated cAMP increase induced by prostacyclin, $\mathrm{PGE}_{2}$ or isoproterenol which activate ACs through Gs-coupled receptors endogenously or heterologously expressed. There are numerous methods to determine intracellular cAMP concentrations but the most reliable are ELISA (commercially available) and newly introduced genetic probes, such as pGloSensor ${ }^{\mathrm{TM}}$ 22F cAMP from Promega. The genetic probes offer great advantage due to the low costs of the assay and also because they allow real-time visualization of cAMP accumulation in living cells.

The selection of the appropriate functional assay during the preparation of a screening campaign is a critical step. Needless to say, in the case of oGPCRs, no information is in general available as to what type of G-protein the receptor is coupled to. An alternative approach, with very good results, is to use the property of the promiscuous

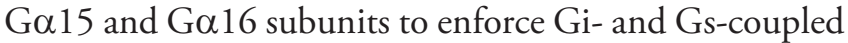
receptors to signal via $\mathrm{PLC}_{\beta}-\mathrm{IP}_{3}-\mathrm{Ca}^{2+}$ pathway $(47,48)$. In this type of assay, reporter cells are transfected with the receptor, the promiscuous $\alpha$ subunits G15 or 16 and the calcium sensitive probe. It is a very versatile method which has been successfully used to identify ligands of Gi- and Gs- and G12/13-coupled receptors (49). Another way to elucidate signaling properties of an oGPCR with unknown G-protein coupling is to overexpress it in a chosen cell line and measure ligand-independent activation (constitutive activity) of specific signaling pathways. This phenomenon has been described to be a result of the receptor overexpression which leads to constitutive activity and it has been succesffully used to identify intracellular signaling characteristics for receptors that induce, for example, cAMP increase after their overexpression $(50,51)$.

$\beta$-arrestins are intracellular scaffold proteins that interact with the activated receptor to promote receptor desensitization (52). Due to their high interaction 
specificity, $\beta$-arrestins can be used as probes to measure receptor activation following ligand stimulation, in a G-protein independent manner. An elegant way of measuring GPCR activation by using $\beta$-arrestins translocation has been recently developed and successfully used to discover novel ligands of oGPCRs $(53,54)$.

Although reversed pharmacology was successfully employed to discover endogenous ligands and agonists of many GPCRs, there are cases where its limits are evidenced due to a different pharmacology and/or biological role of certain receptors. Some of the orphan receptors may simply have ligand-independent functions. Several examples include $\mathrm{GABA}_{\mathrm{B}}, \mathrm{GPR} 50$ and the constitutively active receptors.

The metabotropic gamma-aminobutyric acid $\mathrm{B}$ (GABAB) receptor which is expressed in the brain, is an obligatory heterodimer composed of two $G_{A B A_{B 1}}$ and $\mathrm{GABA}_{\mathrm{B} 2}$ subunits. Interestingly, $\mathrm{GABA}_{\mathrm{B} 1}$ subunit provides GABA-binding site whereas $\mathrm{GABA}_{\mathrm{B} 2}$ facilitates trafficking of $G_{A B A_{B 1}}$ to the cells surface and is required for G-protein coupling but is unable to bind GABA (55).

GPR50 is an orphan receptor predominantly expressed in the brain and it shares structural homology with MT1 and MT2 melatonin receptor subfamily which are activated by the circadian hormone melatonin. Although GPR50 forms in vitro heterodimers with both MT1 and MT2, only interaction with MT1 appears to have functional effects as GPR50 impairs MT1-induced activation of adenylyl-cyclase and subsequent cAMP-dependent pathway. Interestingly, GPR50/MT1 heterodimer completely inhibits high-affinity melatonin binding and receptor-induced G-protein activation (56).

Constitutively activated receptors are receptors which are able to induce the activation of specific G-protein-mediated signaling pathways in the absence of a ligand (57). Thus they are thought to be still orphan receptors and have ligand-independent functions. Constitutive signaling of some GPCRs seems to be induced by mutations which are also associated to various pathological states (58-60) and therefore this pathway is under intense pharmacological surveillance. For example, activating mutations in the thyroid stimulating hormone (TSH) receptor, which plays critical roles in thyroid gland growth and functions, cause toxic adenoma as well as familial and sporadic nonautoimune hyperthyroidism (61).

\section{FORWARD PHARMACOLOGY}

Forward pharmacology (classical pharmacology or phenotypic drug discovery) is based on the phenotypic screening of libraries consisting of natural or synthetic compounds to identify those which have a desirable effect. Historically, forward pharmacology precedes reverse pharmacology in the sense that the biological effects of numerous substances were discovered long before even the receptor concept was proposed. For example, as early as in the $19^{\text {th }}$ century, pilocarpine and atropine were thought to "compound" with a physiological substance present in the target organ to trigger observed effects (such as salivary secretion in dogs). With the advance of metabolomics, the number of metabolites identified in body fluids steadily increased to over 5000. Many of them have unknown biological roles and may even serve as ligands of known or orphan GPCRs. A comprehensive list of metabolites and their description can be found at http://www.hmdb.ca/. Another useful approach to generate a portofolio of putative ligands of a GPCR relies on computer-based virtual ligand screening (VLS) using GPCR's crystal structure as template, when available (62). Structure-based VLS has been successful in identifying new ligands of GPCRs (63)

The central task of the forward pharmacology in GPCR deorphanization is the identification of the mechanism of action of a ligand for which already exist solid evidences of its biological role. As opposite to reverse pharmacology, in this case a ligand is used to find the cognate receptor. In its simplest way, a collection of receptors is individually expressed in a reporter cell line and ligand-induced activation of each receptor is determined and compared to the effect on cells that do not express the receptor. The selection of the receptors is usually based on the information regarding the expression of receptors in the tissues where the ligand is active. A more complex strategy in the identification of a receptor for a particular ligand starts with finding a cellular system where the metabolite/compound is able to activate a GPCR-mediated pathway (Fig. 1). It is then followed by pharmacological analyses of the cellular effect of the ligand at different concentrations (concentration-dependency), its sensitivity to several inhibitors of G-proteins and, where possible, determination of stereospecific effects. All these experiments conclude with a pharmacological profile of the candidate ligand and it is known as ligand "validation". The next step is the discovery of the putative receptor. A number of considerations have to be taken into account at this stage. First of all, from all of the above experiments there is no indication that only one receptor mediates the observed cellular effects. Secondly, it cannot be excluded a more complex signaling pathway involving a GPCR which is necessary but not critical in the mechanism of action of the metabolite/compound. Lastly, the ligand can induce the observed effects after being metabolized to another active species which in turn can activate a GPCR (secondary effect). In order to identify the cognate receptors several converging strategies may be employed.

Expression analysis of all known and predicted GPCRs in the cell type where the ligand is active can provide very useful information. Based on the G-protein coupling studies in the "validation" step, the list of potential receptors can be significantly narrowed down. For example, if the 
ligand induces cellular cAMP accumulation, the candidate receptors to be further tested are the ones which are known to be Gs-coupled. However, as in the case of the unknown intracellular coupling of the oGPCRs, individual testing of each oGPCR is the safest approach. On the other hand, there is a very high chance that the ligand activates a signaling pathway only in one cell type as it is inactive in others. Expression analysis can be effectively used in this situation to compare receptors expressed in the responsive cells with those in the cells were the ligand was inactive. Differential expression analysis can be a powerful tool, especially if more than one cell type is analyzed for responsiveness to a ligand and can be expanded for a portfolio of metabolites/compounds. Such a strategy has been used to identify the receptor which mediates cAMP accumulation in a human megakaryocytic leukemia cell line (MEG-01) and vasorelaxation of arterial segments from mouse induced by the arachidonic acid metabolite, 19-hydroxyeicosatetraenoic acid, 19(S)-HETE (64).

Another efficient strategy to identify the cognate receptor for a ligand is to determine its effect in cells transfected with siRNA targeting individual known and predicted GPCR mRNAs (functional siRNA screening). If the ligand has a significantly lower effect in cells transfected with siRNA against mRNA of a particular GPCR, then this receptor becomes a strong candidate as mediator of the observed cellular effects. Confirmation of the candidate receptor should be performed by expressing candidate receptors in a reporter cell line and determination of receptor activation by the ligand. Although a powerful method, functional siRNA screening requires intense preparative steps. For instance, it is useful to choose the siRNA library/assay conditions that efficiently allow the "re-discovery" of a known receptor by using its endogenous ligand/agonist. As an example, U46619, an agonist of thromboxane A2 (TXA2R) receptor (65), can be tested on responsive cells to determine whether after screening on cells transfected with the siRNA library only siRNAs against TXA2R can strongly reduce the effect of U46619. Accordingly, several other known ligands, activating distinct intracellular signaling pathways should be analyzed before entering a large deorphanization campaign with an unpaired ligand. As proof-of-principle example, by applying this technology it was shown that ricinoleic acid, which is a major component of castor oil used for millennia for its laxative and labor-inducing effects, induces pharmacological effects such as intestinal and uterus contraction by acting as a ligand of prostaglandin E2 receptor, subtype EP3 (66).

\section{CONCLUSIONS}

In a practical sense, reverse and forward pharmacology are not just separated strategies. For example, a receptor can be deorphanized by forward pharmacology and then the reverse pharmacology can be used to further discover agonists and antagonists. An example can be the identification of a family of receptors involved in nutrient sensing by binding hydroxy-carboxylic acids resulted from $\beta$-oxidation of fatty acids (67).

Although the deorphanization of oGPCRs by reverse and forward pharmacology has fundamentally contributed to our understanding of pathophysiology, it is worth noting that the peak of ligand-receptor pairing has been reached in 2003. After that, the deorphanization rate has steadily declined. A reason for the lower rate of deorphanization in the last years may be the increasing costs of ligand screening and the likelihood of the ligand-identification failure. Although pharma companies face the expiration of patents for blockbuster drugs and thus are forced to find new drug targets, they also face increase safety rules and regulations resulting in a high number of leads that fail to reach the higher phases in drug approval. Even if an important receptor is deorphanized and modulators of its activity are of therapeutic importance, it would take many years and very high costs to reach final phases of drug approval. Thus, the interest of the major companies appears to be shifted back towards known targets where development of new compounds with a better pharmacology may be more beneficial. Still, this leaves academia an important role to try understanding the biological function of the remaining oGPCRs.

Another explanation for the decrease rate of deorphanization is that many oGPCRs are phylogenetically distant from known GPCRs, suggesting that they might have completely new ligands and biological roles. From an academic point, this is of the utmost interest. Furthermore, it is also possible that classic deorphanization assays, which rely on the G-protein-dependent signaling pathways, may fail to uncover oGPCRs that can signal in a G-protein independent manner (68).

The deorphanization process is not always flawless. Initial identification claiming successful oGPCR-ligand pairing requires confirmation by independent groups thus leading to possible controversies sometimes persisting for several years. Several examples can be used to learn more about the difficulties encountered during receptor deorphanization. Such examples include GPR68 (OGR1) and GPR 4 which have been initially described as a lipid receptors but could not be confirmed by others, data being thus retracted (69). Another interesting example is GPR30 where controversial features include its subcellular localization and its capacity to bind estrogen thus supporting the notion of non-genomic effects of steroids mediated by GPCRs. Despite intense research in the last years, no clear consensus has been reached so far (70-72).

GPCR heterodimerization has been described as another structural feature with signaling and pharmacology consequences $(73,74)$. It would be interesting to choose 
oGPCRs that show overlapping expression patterns and identify possible oGPCR heterodimers which could be further exploited in screening campaigns. On the other hand, the recent development of metabolomics resulted in the identification of a large number of new metabolites which should also be included in the compound libraries to be tested for potential agonistic/antagonistic effects on known or orphan GPCRs.

The success in receptor-ligand pairing in the last years required the convergence of at least three scientific areas: genomics, metabolomics and cellular biology, through the development of versatile high-throughput screening methods. More challenges as well as interesting questions and answers lie ahead as still a large number of oGPCR await pharmacological characterization.

Acknowledgements: I would like to thank Boris Strilic for critically reading the manuscript.

Conflict of interests: none declared.

\section{REFERENCES}

1. Wettschureck N, Offermanns S, Mammalian G proteins and their cell type specific functions, Physiol Rev., 85, 1159-1204 (2005).

2. Marinissen MJ, Gutkind JS, G-protein-coupled receptors and signaling networks: emerging paradigms, Trends Pharmacol. Sci., 7, 368-376 (2001).

3. Tang XL, Wang Y, Li DL, Luo J, Liu MY, Orphan G proteincoupled receptors (GPCRs): biological functions and potential drug targets, Acta Pharmacol. Sin., 33, 363-371 (2012).

4. Overington JP, Al-Lazikani B, Hopkins AL, How many drug targets are there? Nat. Rev. Drug Discov., 5, $993-996$ (2006).

5. Fang Y, Kenakin T, Liu C, Editorial: Orphan GPCRs As Emerging Drug Targets, Front Pharmacol., 6, 295 (2015).

6. Civelli O, Reinscheid RK, Zhang Y, Wang Z, Fredriksson R, Schioth HB, G protein-coupled receptor deorphanizations, Annu. Rev. Pharmacol. Toxicol., 53, 127-146 (2013).

7. Dixon RA, Kobilka BK, Strader DJ, Benovic JL, Dohlman HG, Frielle T, et al, Cloning of the gene and $\mathrm{DDN}$ for mammalian beta-adrenergic receptor and homology with rhodopsin, Nature, 321, 75-79 (1986).

8. Chung S, Funakoshi T, Civelli O, Orphan GPCR research, Br. J. Pharmacol., 153 Suppl 1, S339-S346 (2008).

9. Godfrey PA, Malnic B, Buck LB, The mouse olfactory receptor gene family, Proc. Natl. Acad. Sci. U.S.A., 7, 2156-2161 (2004).

10. Malnic B, Godfrey PA, Buck LB, The human olfactory receptor gene family, Proc. Natl. Acad. Sci. U.S.A., 8, 2584-2589 (2004).

11. Bjarnadottir TK, Gloriam DE, Hellstrand SH, Kristiansson H, Fredriksson R, Schioth HB, Comprehensive repertoire and phylogenetic analysis of the $G$ protein-coupled receptors in human and mouse, Genomics, 3, 263-273 (2006).

12. Lee JA, Uhlik MT, Moxham CM, Tomandl D, Sall DJ, Modern phenotypic drug discovery is a viable, neoclassic pharma strategy, J. Med. Chem., 55, 4527-4538 (2012).

13. Trivellin G, Bjelobaba I, Daly AF, Larco DO, Palmeira L, Faucz FR, et al, Characterization of GPR101 transcript structure and expression patterns, J. Mol. Endocrinol., 57, 97-111 (2016).

14. Trivellin G, Daly AF, Faucz FR, Yuan B, Rostomyan L, Larco $\mathrm{DO}$, et al, Gigantism and acromegaly due to Xq26 microduplications and GPR101 mutation, N. Engl. J. Med., 371, 2363-2374 (2014).

15. Edson MA, Lin YN, Matzuk MM, Deletion of the novel oocyteenriched gene, Gpr149, leads to increased fertility in mice, Endocrinology, 151, 358-368 (2010).

16. Cui J, Ding Y, Chen S, Zhu X, Wu Y, Zhang M, et al, Disruption of Gpr 45 causes reduced hypothalamic POMC expression and obesity, J. Clin. Invest., 126, 3192-3206 (2016).

17. Osborn O, Oh DY, McNelis J, Sanchez-Alavez M, Talukdar S, $\mathrm{Lu} \mathrm{M}$, et al, G protein-coupled receptor 21 deletion improves insulin sensitivity in diet-induced obese mice,

J. Clin. Invest., 122, 2444-2453 (2012).

18. Chambers JK, Macdonald LE, Sarau HM, Ames RS, Freeman K, Foley JJ, et al, A G protein-coupled receptor for UDP-glucose, J. Biol. Chem., 275, 10767-1071 (2000).

19. Lee MJ, Van Brocklyn JR, Thangada S, Liu CH, Hand AR, Menzeleev R, et al, Sphingosine-1-phosphate as a ligand for the $G$ protein-coupled receptor EDG-1, Science, 279, 1552-1555 (1998).

20. An S, Bleu T, Huang W, Hallmark OG, Coughlin SR, Goetzl EJ, Identification of cDNAs encoding two G protein-coupled receptors for lysosphingolipids, FEBS Lett., 3, 279-282 (1997).

21. Rosen H, Stevens RC, Hanson M, Roberts E, Oldstone MB, Sphingosine-1-phosphate and its receptors: structure, signaling, and influence, Annu. Rev. Biochem., 82, 637-662 (2013).

22. Rasmussen SG, DeVree BT, Zou Y, Kruse AC, Chung KY, Kobilka TS, et al., Crystal structure of the beta 2 adrenergic receptor-Gs protein complex, Nature, 7366, 549-555 (2011).

23. Kumari P, Ghosh E, Shukla AK, Emerging Approaches to GPCR Ligand Screening for Drug Discovery,

Trends Mol. Med., 11, 687-701 (2015).

24. Ngo T, Kufareva I, Coleman J, Graham RM, Abagyan R, Smith NJ, Identifying ligands at orphan GPCRs: current status using structure-based approaches, Br. J. Pharmacol., 20, 2934-2951 (2016).

25. Huang XP, Karpiak J, Kroeze WK, Zhu H, Chen X, Moy SS, et al., Allosteric ligands for the pharmacologically dark receptors GPR68 and GPR65, Nature, 7579, 477-483 (2015).

26. Manglik A, Lin H, Aryal DK, McCorvy JD, Dengler D, Corder $\mathrm{G}$, et al, Structure-based discovery of opioid analgesics with reduced side effects, Nature, 7619, 185-190 (2016).

27. Budzik B, Garzya V, Shi D, Walker G, Woolley-Roberts M, Pardoe J, et al, Novel N-Substituted Benzimidazolones as Potent, Selective, CNS-Penetrant, and Orally Active M1 mAChR Agonists, ACS Med. Chem. Lett., 6, 244-248 (2010).

28. Regard JB, Sato IT, Coughlin SR, Anatomical profiling of G protein-coupled receptor expression, Cell, 3, 561-571 (2008).

29. Ito J, Ito M, Nambu H, Fujikawa T, Tanaka K, Iwaasa H, et al, Anatomical and histological profiling of orphan G-protein-coupled receptor expression in gastrointestinal tract of $C 57 B L / 6 J$ mice, Cell Tissue Res., 2, 257-269 (2009).

30. Brown AJ, Goldsworthy SM, Barnes AA, Eilert MM, Tcheang L, Daniels D, et al, The Orphan G protein-coupled receptors GPR 41 and GPR43 are activated by propionate and other short chain carboxylic acids, J. Biol. Chem., 278, 11312-11319 (2003).

31. Briscoe CP, Tadayyon M, Andrews JL, Benson WG, Chambers JK, Eilert MM, et al, The orphan $G$ protein-coupled receptor GPR4O is activated by medium and long chain fatty acids, J. Biol. Chem., 278, 11303-11311 (2003).

32. Itoh Y, Kawamata Y, Harada M, Kobayashi M, Fujii R, Fukusumi 
S, et al, Free fatty acids regulate insulin secretion from pancreatic beta cells through GPR40, Nature, 422, 173-176 (2003).

33. Sakurai T, Amemiya A, Ishii M, Matsuzaki I, Chemelli RM, Tanaka $\mathrm{H}$, et al, Orexins and orexin receptors: a family of hypothalamic neuropeptides and $G$ protein-coupled receptors that regulate feeding behavior, Cell, 92, 573-585 (1998).

34. Saito Y, Nothacker HP, Wang Z, Lin SH, Leslie F, Civelli O, Molecular characterization of the melanin-concentrating-hormone receptor, Nature, 400, 265-269 (1999).

35. Chambers J, Ames RS, Bergsma D, Muir A, Fitzgerald LR, Hervieu G, et al, Melanin-concentrating hormone is the cognate ligand for the orphan G-protein-coupled receptor SLC-1, Nature, 400, 261-265 (1999).

36. Howard AD, Feighner SD, Cully DF, Arena JP, Liberator PA, Rosenblum CI, et al, A receptor in pituitary and hypothalamus that functions in growth hormone release,

Science, 273, 974-977 (1996).

37. Kojima M, Hosoda H, Date Y, Nakazato M, Matsuo H, Kangawa K, Ghrelin is a growth-hormone-releasing acylated peptide from stomach, Nature, 402, 656-660 (1999).

38. Luttrell LM, Transmembrane signaling by G protein-coupled receptors, Methods Mol. Biol., 332, 3-49 (2006).

39. Ritter SL, Hall RA, Fine-tuning of GPCR activity by receptor-interacting proteins, Nat. Rev. Mol. Cell Biol., 10, 819-830 (2009).

40. Magalhaes AC, Dunn H, Ferguson SS, Regulation of GPCR activity, traffcking and localization by GPCR-interacting proteins, Br. J. Pharmacol., 165, 1717-1736 (2012).

41. Milligan G, Principles: extending the utility of [35S]GTP gamma S binding assays, Trends Pharmacol. Sci., 24, 87-90 (2003).

42. Thomsen W, Frazer J, Unett D, Functional assays for screening GPCR targets, Curr. Opin. Biotechnol., 16, 655-665 (2005).

43. Zhang R, Xie X, Tools for GPCR drug discovery, Acta Pharmacol. Sin., 33, 372-384 (2012).

44. Paredes RM, Etzler JC, Watts LT, Zheng W, Lechleiter JD, Chemical calcium indicators, Methods, 46, 143-151 (2008).

45. Baubet V, Le Mouellic H, Campbell AK, Lucas-Meunier E, Fossier P, Brulet P, Chimeric green fluorescent protein-aequorin as bioluminescent $\mathrm{Ca}^{2+}$ reporters at the single-cell level, Proc. Natl. Acad. Sci. U.S.A., 97, 7260-7265 (2000).

46. Beets I, Lindemans M, Janssen T, Verleyen P, Deorphanizing $g$ protein-coupled receptors by a calcium mobilization assay, Methods Mol. Biol., 789, 377-391 (2011).

47. Offermanns S, Simon MI, G alpha 15 and $G$ alpha 16 couple a wide variety of receptors to phospholipase C, J. Biol. Chem., 270, 15175-15180 (1995).

48. Milligan G, Marshall F, Rees S, G16 as a universal G protein adapter: implications for agonist screening strategies, Trends Pharmacol. Sci., 17, 235-237 (1996).

49. Emkey R, Rankl NB, Screening G protein-coupled receptors: measurement of intracellular calcium using the fluorometric imaging plate reader, Methods Mol. Biol., 565, 145-158 (2009).

50. Bohnekamp J, Schoneberg T, Cell adhesion receptor GPR133 couples to Gs protein, J. Biol. Chem., 49, 41912-41916 (2011).

51. Bates B, Zhang L, Nawoschik S, Kodangattil S, Tseng E, Kopsco $\mathrm{D}$, et al, Characterization of Gpr101 expression and G-protein coupling selectivity, Brain Res., 1, 1-14 (2006).

52. Walther C, Ferguson SS, Arrestins: role in the desensitization, sequestration, and vesicular trafficking of $G$ protein-coupled receptors, Prog. Mol. Biol. Transl. Sci., 118, 93-113 (2013).

53. Kroeze WK, Sassano MF, Huang XP, Lansu K, McCorvy JD, Giguere PM, et al, PRESTO-Tango as an open-source resource for interrogation of the druggable human GPCRome,

Nat. Struct. Mol. Biol., 5, 362-369 (2015).

54. Sato S, Huang XP, Kroeze WK, Roth BL, Discovery and Characterization of Novel GPR39 Agonists Allosterically Modulated by Zinc, Mol. Pharmacol., 6, 726-737 (2016).

55. Kniazeff J, Galvez T, Labesse G, Pin JP, No ligand binding in the $G B 2$ subunit of the $G A B A(B)$ receptor is required for activation and allosteric interaction between the subunits,

J. Neurosci., 22, 7352-7361 (2002).

56. Levoye A, Dam J, Ayoub MA, Guillaume JL, Couturier C, Delagrange P, et al, The orphan GPR50 receptor specifically inhibits MT1 melatonin receptor function through heterodimerization, EMBO J., 25, 3012-3023 (2006)..

57. Seifert R, Wenzel-Seifert K, Constitutive activity of G-proteincoupled receptors: cause of disease and common property of wild-type receptors, Naunyn Schmiedebergs Arch. Pharmacol., 366, 381-416 (2002).

58. Rosenkilde MM, Kledal TN, Schwartz TW, High constitutive activity of a virus-encoded seven transmembrane receptor in the absence of the conserved DRY motif (Asp-Arg-Tyr) in transmembrane helix 3, Mol. Pharmacol., 68, 11-19 (2005).

59. Rosenkilde MM, Benned-Jensen T, Andersen H, Holst PJ, Kledal TN, Luttichau HR, et al, Molecular pharmacological phenotyping of EBI2. An orphan seven-transmembrane receptor with constitutive activity, J. Biol. Chem., 281, 13199-13208 (2006).

60. Tao YX, Constitutive activation of $G$ protein-coupled receptors and diseases: insights into mechanisms of activation and therapeutics, Pharmacol. Ther., 120, 129-148 (2008).

61. Kopp P, The TSH receptor and its role in thyroid disease, Cell Mol. Life Sci., 58, 1301-1322 (2001).

62. Kolb P, Ferreira RS, Irwin JJ, Shoichet BK, Docking and chemoinformatic screens for new ligands and targets,

Curr. Opin. Biotechnol., 4, 429-436 (2009).

63. Kooistra AJ, Roumen L, Leurs R, de Esch IJ, de Graaf C, From heptahelical bundle to hits from the Haystack: structure-based virtual screening for GPCR ligands, Methods Enzymol., 522, 279-336 (2013).

64. Tunaru S, Chennupati R, Nusing RM, Offermanns S, Arachidonic Acid Metabolite 19(S)-HETE Induces Vasorelaxation and Platelet Inhibition by Activating Prostacyclin (IP) Receptor, PLoS One, 11, e0163633 (2016).

65. Matsuoka T, Narumiya S, Prostaglandin receptor signaling in disease, Scientific World Journal, 7, 1329-1347 (2007).

66. Tunaru S, Althoff TF, Nusing RM, Diener M, Offermanns S, Castor oil induces laxation and uterus contraction via ricinoleic acid activating prostaglandin EP3 receptors,

Proc. Natl. Acad. Sci. U.S.A., 109, 9179-9184 (2012).

67. Ahmed K, Tunaru S, Offermanns S, GPR109A, GPR109B and GPR81, a family of hydroxy-carboxylic acid receptors, Trends Pharmacol. Sci., 30, 557-562 (2009).

68. Gurevich VV, Gurevich EV, Overview of different mechanisms of arrestin-mediated signaling, Curr. Protoc. Pharmacol., 67, Unit 210 1-9 (2014).

69. Seuwen K, Ludwig MG, Wolf RM, Receptors for protons or lipid messengers or both? J. Recept. Signal Transduct. Res., 5-6, 599-610 (2006).

70. Filardo EJ, Quinn JA, Bland KI, Frackelton AR Jr, Estrogen-induced activation of Erk-1 and Erk-2 requires the $G$ protein-coupled receptor homolog, GPR30, and occurs via trans-activation of the epidermal growth factor receptor through release of HB-EGF, Mol. Endocrinol., 10, 1649-1660 (2000).

71. Prossnitz ER, Oprea TI, Sklar LA, Arterburn JB, The ins and outs of GPR30: a transmembrane estrogen receptor,

J. Steroid Biochem. Mol. Biol., 3-5, 350-353 (2008).

72. Otto C, Rohde-Schulz B, Schwarz G, Fuchs I, Klewer M, Brittain D, et al, G protein-coupled receptor 30 localizes to the endoplasmic reticulum and is not activated by estradiol, Endocrinology, 10, 4846-4856 (2008).

73. Gurevich VV, Gurevich EV, How and why do GPCRs dimerize? Trends Pharmacol. Sci., 5, 234-240 (2008). 